\title{
openheart Spontaneous coronary artery dissection: contemporary aspects of diagnosis and patient management
}

\author{
Fernando Macaya, Pablo Salinas, Nieves Gonzalo, Antonio Fernández-Ortiz, \\ Carlos Macaya, Javier Escaned
}

\begin{abstract}
- Additional material is published online only. To view please visit the journal online (http://dx.doi.org/10.1136/ openhrt-2018-000884).
\end{abstract}

To cite: Macaya F, Salinas $P$, Gonzalo N, et al. Spontaneous coronary artery dissection: contemporary aspects of diagnosis and patient management. Open Heart 2018;5:e000884. doi:10.1136/ openhrt-2018-000884

Received 19 June 2018 Revised 29 August 2018 Accepted 31 August 2018
Check for updates

(c) Author(s) (or their employer(s)) 2018. Re-use permitted under CC BY-NC. No commercial re-use. See rights and permissions. Published by BMJ.

Servicio de Cardiología, Hospital Clínico San Carlos, Universidad Complutense, IdISSC, Madrid, Spain

Correspondence to Javier Escaned; escaned@ secardiologia.es

\begin{abstract}
Spontaneous coronary artery dissection is an increasingly recognised cause of acute coronary syndromes, especially in young and middle-age women. Recognising its particularities and differences with atherosclerotic disease is central for appropriately identifying and approaching these patients. The authors review the current state of knowledge on spontaneous coronary artery dissection and provide practical recommendations for the diagnosis and management of this condition, both in the acute and convalescence phases.
\end{abstract}

\section{INTRODUCTION}

Spontaneous coronary artery dissection (SCAD) is an important non-atherosclerotic aetiology underlying acute coronary syndromes (ACS) or sudden cardiac death in young and middle-age women. Knowledge of the pathophysiology, diagnosis and management of SCAD has exponentially increased over the last years, ${ }^{1-12}$ leading to more awareness and enhanced recognition by cardiologists worldwide. This also explains the creation of dedicated working groups, ${ }^{13} 14$ alongside with e-platforms intended to gather patients with SCAD, and get them involved in research projects. ${ }^{15}$ Similarly, patients have initiated social networks to increase SCAD awareness and promote self-support and research. $^{16}$

Simultaneously to this breakthrough, cardiologists are in the phase of integrating the new evidence and familiarising with this distinct entity, from its etiopathogenesis to the patient profile and outcomes. At present, clinical approach and management of SCAD is still too heterogeneous and, as a consequence, patients perceive disinformation and lhelplessness. ${ }^{17-19}$ Following the two positioning papers published recently, ${ }^{13} 14$ the present review aims to put together and synthesise the current state of the knowledge in SCAD. This article is intended to provide practical tips and guidance for clinicians dealing with this condition. Through the use of patient-centred algorithms and clear messages for practical application, we hope that the present work contributes to an improved and more uniform management of SCAD.

\section{DEFINITION}

SCAD is a non-traumatic, non-iatrogenic and non-atherosclerotic coronary artery disorder that expresses clinically as an ACS or, less often, as arrhythmia or sudden cardiac death. ${ }^{20-22}$ The pathology consists in the acute and spontaneous separation of the coronary artery wall layers that leads to the generation of an intramural space (false lumen), which may or may not be communicated with the true lumen through an intimal tear (flap fenestration). In any case, the pathological hallmark is the presence of a myoendothelial tissue lamina (intimomedial flap) dividing the two vascular spaces. The initiator of this phenomenon seems to be a haemorrhage at some level within the tunica media and adventitia, although it remains unclear whether the intimal tear, when present, could be the primary event. ${ }^{13}$

Myocardial ischaemia and associated symptoms are thought to develop as a result of any of the following: (i) significant bulging of the compressed intima by an intramural haematoma; (ii) extension of the dissection by antegrade coronary flow causing an obstructive false vascular lumen; (iii) thrombosis associated to disturbed haemodynamics and exposure of deep components of the vessel wall to the blood stream; and (iv) the arterial dissection itself and subsequent healing process could potentially cause chest pain in the absence of myocardial ischaemia.

SCAD aetiology is not fully understood but is frequently explained as a combination of patient susceptibility and a variety of triggering factors. As per the modern 
definition of SCAD ${ }^{13}{ }^{14}$ external high-energy traumatisms (eg, traffic accident), direct vessel instrumentation or complicated atherosclerosis should be excluded. ${ }^{23}$ The latter deserves further clarification as the presence of atherosclerosis is not an exclusion criterion itself; rather, the cause of the dissection cannot be attributable to a complicated atherosclerotic plaque that initiates the dissection (atherosclerotic plaque erosion, disruption or rupture). This differential diagnosis may be troublesome and usually involves intracoronary imaging (ICI), which is discussed in a specific section. Last but not least, when acute aortic dissection (Stanford type A) is simultaneously presented with coronary dissection, the latter is usually a secondary diagnosis in the context of the former.

- Spontaneous intramural haemorrhage, with or without intimal disruption, are distinctive pathological features of SCAD that ultimately translate clinically as a classic acute coronary syndrome or life-threating arrhythmia.

- SCAD is a different pathological entity than coronary dissection associated to atherosclerosis, direct vessel instrumentation, high-energy external traumatism or primary aortic dissection.

\section{PATIENT PROFILE}

\section{Epidemiology}

Although the true incidence of SCAD is still uncertain, in modern series it has been reported to represent $1.1 \%-4 \%$ of all ACS cases ${ }^{5824}$ and has been identified as the cause of $15 \%-35 \%$ of ACS in women under 50 years. ${ }^{6825}$ Moreover, it has been suggested to underlie $0.5 \%$ of sudden cardiac deaths. ${ }^{26}$ SCAD is believed to be underdiagnosed at patient level (misdiagnosis of ACS in young otherwise healthy women) and in angiographic studies (oversight of angiographic subtle signs). However, with the advent of high-sensitivity troponin, the readiness of invasive angiography and availability of ICI, a higher number of SCAD cases can now be detected. All these advances have also permitted a better depiction of recognisable angiographic patterns that can raise the suspicion and, in many cases, establish the diagnosis of SCAD. ${ }^{27-29}$

Table 1 summarises modern (from 2012) well-described SCAD series/cohorts $(n=1004)$. This entity predominantly affects female gender, which represent $81 \%-100 \%$ (weighed average 91.6\%). Mean age ranges from 45 to 56 (weighed average 50+/-9.8) years presenting normal distributions within series, where cases $<30$ or $>80$ years are rare. ${ }^{1-4} 6-911$ Caucasian or white race is reported in US and Canadian series as much as $76 \%-82 \%$ of the patients, ${ }^{29}$ though this is likely influenced by local demographics and referral bias. Cardiovascular risk factors, although not necessarily absent, are less prevalent in the SCAD population when compared with ACS population with similar age and sex. ${ }^{16830}$

\section{Associated conditions and precipitating factors}

An array of conditions frequently coexists with SCAD; however, it is not fully understood whether they act as preconditioners, precipitators or are just bystanders. Of note, a considerable number of patients do not present with these conditions and are sometimes labelled as idiopathic SCAD.

\section{Pregnancy and delivery}

SCAD is the leading cause of pregnancy-related acute myocardial infarction (MI), prevailing over all other aetiologies such as atherosclerosis, thromboembolism or coronary spasm. It is estimated that $40 \%$ of MIs during pregnancy are caused by SCAD. ${ }^{31}$ A population-based cohort study conducted in North America showed that SCAD occurred in 1.8/100 000 pregnancies, though this figure is likely underestimated. ${ }^{32}$ All this might have contributed to the perception that SCAD was a pregnancy-associated condition. However, in contemporary series only $2.4 \%-9 \%$ of SCAD cases occur during pregnancy or puerperium. ${ }^{2679}$

The diagnosis of pregnancy-associated SCAD (P-SCAD) is based on the temporal association with delivery. Tweet et al proposed P-SCAD as that occurring during pregnancy and within the first three months post partum. ${ }^{12}$ This definition is based on the peak incidence of SCAD events within that period alongside the marked shifts in haemodynamics and hormonal exposure happening soon after delivery. ${ }^{33}$ Alternatively, Saw et al proposed a more inclusive definition, considering up to 24 months post partum on the grounds of the persistent hormonal exposure in breastfeeding women. ${ }^{20}$

The temporal limit to designate P-SCAD remains unclear. The importance of labelling an association with pregnancy resides in recent data that indicate a higher risk profile for these patients. Patients with P-SCAD present with more extensive coronary involvement (more left main, proximal and multivessel affection) and larger ischaemic myocardium, which leads to more frequent revascularisation and mechanical support, ultimately resulting in worse outcomes. ${ }^{12} 3435$

A possible explanation for the higher risk of P-SCAD is the deleterious combination of hormone-mediated arterial wall weakening (substrate) and pregnancy-related haemodynamic and neurohormonal stressors (triggers). ${ }^{31}$ Data suggest that, in case of multigravidity and/ or multiparity, each pregnancy/delivery might act as additive exposures, increasing the risk of presenting P-SCAD in the short and long term. ${ }^{36}$ These exposures may also increase the risk of developing non-pregnancy-associated SCAD in a lifetime, eventually behaving as a risk factor for any type of SCAD ${ }^{37}$ Therefore, it could be hypothesised that pregnancies (and deliveries) prepare the substrate, and the superimposition of a certain trigger ultimately leads to SCAD. When this trigger is related to pregnancy, delivery or puerperium, SCAD develops on top of an extraordinary vulnerable situation that derives into this more aggressive clinical manifestation that is P-SCAD. 


\begin{tabular}{|c|c|c|c|c|c|c|c|c|}
\hline Country, Year & $\mathbf{N}$ & Age & Female (\%) & Smoker (\%) & HTN (\%) & DLP (\%) & DM (\%) & FH (\%) \\
\hline Portugal, $2018^{10}$ & 27 & 56 (11) & 82 & 19 & 56 & 44 & 0 & n.r \\
\hline Canada, $2017^{9}$ & 327 & $52.5(9.6)$ & 91 & 10 & 36 & 26 & 5 & 33 \\
\hline France, $2017^{8}$ & 55 & $50.1(10.1)$ & 100 & 22 & 27 & 11 & 4 & 22 \\
\hline Australia, $2016^{7}$ & 40 & $45(10)$ & 95 & 8 & 18 & 10 & 5 & 28 \\
\hline Japan, $2016^{6}$ & 63 & $46(10)$ & 94 & 32 & 33 & 22 & 0 & 8 \\
\hline Australia, $2016^{5}$ & 21 & $53.3(8.8)$ & 95 & 48 & 48 & 48 & 5 & 24 \\
\hline Switzerland, $2015^{4}$ & 64 & $53(11.2)$ & 94 & 28 & 45 & 52 & 0 & 19 \\
\hline Italy, $2015^{3}$ & 134 & $52(11)$ & 81 & 34 & 51 & 33 & 2 & 25 \\
\hline USA, $2014^{2}$ & 246 & $45.3(8.9)$ & 96 & 2 & 34 & 27 & 2 & n.r. \\
\hline Spain, $2012^{1}$ & 27 & $52(10)$ & 85 & 52 & 37 & 33 & 4 & n.r. \\
\hline Total/w.a. & 1,022 & $50(9.8)$ & 91.6 & 16.4 & 37.6 & 28.2 & 2.9 & 26.6 \\
\hline
\end{tabular}

Age is in described as mean years and standard deviation

DLP, dyslipidaemia; DM, diabetes mellitus; FH, family history of coronary disease; HTN, hypertension; n.r, not reported; w.a, weighed average.

Nevertheless, it is intriguing why some patients develop P-SCAD during the first puerperium, while others do after several uneventful pregnancies. ${ }^{12}$ It seems that pregnancies/deliveries exert different magnitudes of adverse effects on women's vessels according to patient idiosyncratic susceptibility. This is further supported by the fact that millions of healthy women have multiple uneventful childbirths. ${ }^{32}$ It has been proposed that older age at pregnancy could contribute to this susceptibility. ${ }^{12} 3237$

\section{Hormonal therapy}

Like pregnancy, prolonged exposure to exogenous hormonal treatment could potentially increase the risk of developing SCAD in susceptible individuals, and perhaps increase the risk of recurrence in SCAD survivors. ${ }^{12} 20$ However, this hypothesis has not been confirmed in a recent study looking for recurrence predictors. ${ }^{9}$

\section{Fibromuscular dysplasia}

Recent data showing a high prevalence of extracoronary arterial abnormalities in SCAD patients suggest that SCAD may be an organ-specific manifestation of a systemic vascular disorder or arteriopathy. Within the array of abnormalities encountered, the most frequently identified one has been the 'string of beads' pattern (serial stenoses), hallmark of fibromuscular dysplasia (FMD) (figure 1).

FMD is an idiopathic non-inflammatory non-atherosclerotic arteriopathy that predominantly affects medium-size arteries, especially the renal and extracranial carotid and vertebral arteries. Cardinal clinical features correlate well with the affected arterial bed: hypertension, bruits, headaches and pulsatile tinnitus. ${ }^{38}{ }^{39}$ Interestingly, migraine is frequently reported by patients with SCAD (33\%-43\%). ${ }^{279}$ Although these symptoms/signs are not specific of FMD, the presence of them should raise suspicion and prompt further investigation.
The dominant histopathological substrate of FMD is medial fibroplasia that frequently present with alternating areas of degeneration and thickened

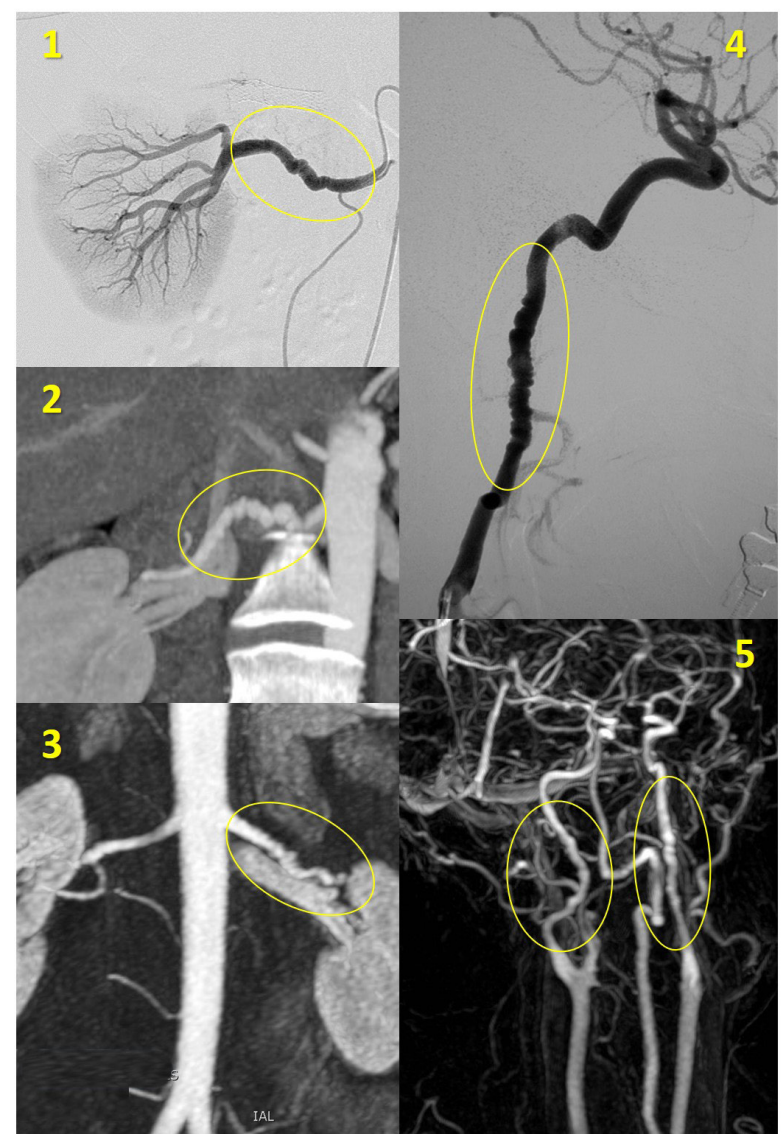

Figure 1 Multimodal angiography of typical fibromuscular dysplasia pattern. Typical radiographic appearance of fibromuscular dysplasia as beading of the renal (panels 1, 2, 3 ) and carotid (panels 4,5) arteries, detected with invasive angiography (1.4), CT (2) and magnetic resonance $(3,5)$. 
fibromuscular ridges, causing a string of stenosis and dilatations (the so-called 'string of beads' or 'beading' pattern). From a diagnostic perspective, FMD may manifest not only as focal or multifocal arterial stenoses, but also as aneurysms, dissections and vessel tortuosity. ${ }^{38} 39$

In North American patients with SCAD, systematic screening with CT angiography or selective invasive angiography have revealed FMD in $45 \%-63 \%$ of them and, importantly, a rate of $\sim 8 \%$ of cerebral aneurisms. ${ }^{940}$ Conversely, data from other cohorts have shown generally lower prevalence of FMD ranging from 13\% to $37 \%$ in series from different countries. ${ }^{4641}$ The heterogeneity in the reported figures may obey to variations in study populations, imaging modalities and protocols, and definitions for FMD.

On the other hand, SCAD is not that common in patients diagnosed with FMD: among patients with documented FMD (in any arterial territory) from the US FMD registry, any arterial dissection was diagnosed in a quarter of the patients with FMD, with the carotid arteries being the preferred territory (16\% overall). Moreover, the prevalence of SCAD among patients with FMD was $<3 \% .^{42}$ Thus, the true nature of the relationship between these two entities remains elusive.

A recent study with optical coherent tomography (OCT) in patients with SCAD and extracoronary FMD depicted a variety of coronary abnormalities other than dissections (tortuosity, stenoses, areas of patchy or diffuse intimal, medial or adventitial abnormalities with thickening/accumulation of varied reflectivity, macrophage infiltration, loss/duplication of elastic membranes and cavitation), suggesting potential mechanisms responsible of their predisposition for SCAD. ${ }^{43}$ Moreover, severe coronary tortuosity, frequently detected in SCAD, may be another manifestation of underlying FMD. ${ }^{2}{ }^{43}$ Diagnostic and therapeutic considerations regarding extracoronary arteriopathy in SCAD are discussed in the convalescence management section below.

\section{Autoimmune or connective tissue disorders}

Coexisting autoimmune or connective tissue disorders such as systemic lupus erythematosus, polyarteritis nodosa, inflammatory bowel disease, polycystic kidney disease, Ehlers-Danlos or Marfan-like syndromes have been also highlighted as potential predisposing/precipitating factors for SCAD. ${ }^{44-52}$ Nevertheless, this relation is mainly described in case reports, as cohort studies data do not suggest a strong association: $0 \%-8 \%$ for connective tissue disorders $^{2895354}$ and 0\%-12\% for autoimmune or inflammatory disorders. ${ }^{189}$ And yet, the coexistence of any of these conditions may be relevant at the level of individual patients presenting with SCAD, thus screening for symptoms and syndromic features has been recommended. ${ }^{14}$ In fact, according to recently presented data from the Canadian registry, connective tissue disorders might have an impact in the occurrence of short-term major adverse cardiovascular events (MACE). ${ }^{35}$
Hypothyroidism might be associated with SCAD. In the series from Vancouver, $13.1 \%$ of the patients had hypothyroidism. ${ }^{9}$ In a study by Camacho-Freire et al,$^{55} 73$ patients with SCAD from two referral centres were compared 1:1 to patients with ACS matched by age, sex and clinical presentation. They found a prevalence of hypothyroidism of $26 \%$ in the SCAD group, which was significantly higher compared with the $8 \%$ prevalence in the control population. Although not elucidated, the effects of the thyroid hormones in the cardiovascular system may explain the potential interplay between thyroid disarrangements and the occurrence of SCAD. ${ }^{55}$

\section{Depression and anxiety disorders at baseline}

Patients with SCAD appear to have traits of psychological disorders more often than other patients with ACS at baseline. ${ }^{30}$ This is partially explained by the fact that depression and anxiety disorders are much more frequent in women than men, and more prevalent in young ages. ${ }^{56}$ Nevertheless, in the recent study by Saw et al, depression and anxiety were present in $22.6 \%$ and $13.5 \%$, respectively, ${ }^{9}$ which is a higher prevalence compared with that of Canadian women of similar age $\left(<7 \%\right.$ and $<10 \%$, respectively). ${ }^{57}$ Psychological repercussions following SCAD are discussed in the convalescence management section below.

\section{Takotsubo cardiomyopathy}

SCAD shares several features with takotsubo syndrome, as ACS presentation, preponderance of female gender, presence of triggers and prompt recovery of coronary and contractile function (not all SCAD cases) ${ }^{365859}$ Therefore, it is important to bear in mind these two entities in the differential diagnosis. Regarding demographics, although both SCAD and takotsubo syndrome mostly occur in women (circa 90\% in both), patients with SCAD are markedly younger in average ( 50 vs $67-70$ years).$^{60} 61$

Several case reports have highlighted the coexistence of these two conditions in the same patient. ${ }^{62} 63$ In this scenario, ICI may play a key role revealing concealed SCAD lesions. ${ }^{6465}$ True coexistence of the two syndromes can only be demonstrated when the SCAD lesion is not blameable of the amount of myocardial dysfunction (ie, coronary and myocardial affection clearly disagree), which is sometimes challenging. In most cases, myocardial dysfunction or stunning resembling takotsubo syndrome can be attributed to SCAD, and then it is called pseudo-takotsubo or takotsubo-like syndrome. Interesting causal links have been proposed for this complex interplay: a common stressor could bring about both entities, or the sole stress produced by suffering one may provoke the other. ${ }^{63}$

\section{Coronary tortuosity and myocardial bridging}

Coronary tortuosity (online supplementary figure A, material 1) in patients with SCAD is fourfold more common than controls. ${ }^{2}$ Although not an idiopathic finding, this characteristic should raise the clinical suspicion for SCAD. Turbulent blood flow patterns in tortuous arteries produce areas of high shear stress where typically SCAD develop. 
Patients with severe tortuosity show a trend towards higher risk of SCAD recurrence, with $80 \%$ of the repeat episodes occurring in tortuous segments. ${ }^{2}$

The presence of a myocardial bridge could hypothetically contribute to unleash SCAD in predisposed arteries by mechanical stress. ${ }^{66}{ }^{67}$ Yet, given its high prevalence, it would be erroneous to adjudicate the entire responsibility of the SCAD to a myocardial bridge.

\section{Familial susceptibility}

Evidence suggesting a genetic predisposition of SCAD is scarce. A marginal number $(\sim 1 \%)$ of SCAD cases have been shown to present familiar aggregation. ${ }^{68}$ For the time being, the only genetic findings are related to connective tissue disorders ${ }^{52-54}$ and represent a minority of the cases. Although research is hampered by the rarity of the condition, genetic data collection should be sought for collaborative studies.

\section{SCAD triggers}

Irrespective of the presence of associated conditions, SCAD is preceded by an identifiable trigger in a considerable proportion of patients. Physical and emotional stressors are the most commonly recognised triggers, ranging widely from $23 \%$ to $77 \%$ in different series. ${ }^{679}$ These digits are higher than those found for physical and emotional factors preceding any type of MI in a large international series $(13.6 \%$ and $14.4 \%$, respectively). ${ }^{69}$

The prevalence of physical and emotional triggers seems to vary with gender. A recent report revealed that among 25 men presenting with SCAD, $11(44 \%)$ were doing an isometric exertion and $6(24 \%)$ reported an emotional stressor prior to the event, which significantly differed from women of the same series $(16 \%, \mathrm{p}=0.004 \%$ and $55 \%$, $\mathrm{p}=0.005$ respectively).$^{70}$ Coughing, retching (Valsalva-like) or altitude sports have been reported also as SCAD triggers, ${ }^{71-74}$ as well as the use of stimulating recreational drugs, high doses of corticosteroids or hormones. ${ }^{75-77}$ It may be hypothesised that a catecholaminergic response related to some of these stressors might lead to a hypertensive peak and increased shear stress ultimately unleashing SCAD.

- Typically, SCAD occurs in middle-age women, with or without cardiovascular risk factors, presenting with acute coronary syndrome. Triggering factors frequently precede the event.

- A minority of SCAD cases occur during or soon after pregnancy. Pregnancy-associated SCAD appear to entail a worse prognosis.

- The diagnosis of SCAD should raise the suspicion of a coexisting medical disorder. Fibromuscular dysplasia is the commonest systemic condition associated to SCAD.

\section{CLINICAL PRESENTATION}

Nearly all patients with SCAD present as typical ACS. Despite progresses in diagnosing ACS, there is still a risk of underdiagnosing it in women owing to their low cardiovascular risk profile or atypical symptoms at presentation. ${ }^{78}$
A high index of suspicion is required to avoid misdiagnosis and appropriately refer the patient for coronary angiography. Although most patients with SCAD present with acute onset chest pain with raise in cardiac biomarkers, a smaller proportion $(11 \%-16 \%)$ present with cardiogenic shock or ventricular arrhythmias. ${ }^{6-8}$ Sudden cardiac death, although likely underestimated, accounts for the least common presentation $(<1 \%) .{ }^{2026}$

The proportion of ST segment elevation myocardial infarction (STEMI) and non-STEMI varies significantly among SCAD series: STEMI 26\%-87\% (weighed average $37 \%$ ), non-STEMI 13\%-77\% (weighed average 63\%). ${ }^{13-11}$ This variation likely owes to the dynamic behaviour of the SCAD lesion and its translation into the ECG. Single-vessel dissection is the most common anatomical presentation, with only $\sim 10 \%$ of SCAD cases presenting with multivessel involvement (the least in non-contiguous vessels). Principal vessels' territories are affected in the following frequencies (not exclusive): left anterior descending $(\sim 57 \%)$, left circumflex $(\sim 32 \%)$, right coronary artery $(\sim 23 \%)$ and left main $(\sim 3 \%) .{ }^{14-11}$ Although not homogeneously reported, it is known that SCAD typically presents in mid to distal segments, with about $10 \%$ involving proximal vessels. ${ }^{34920}$

\section{DIAGNOSIS}

Coronary angiography remains central for SCAD diagnosis. A simplified angiographic classification was described to enhance its recognition. ${ }^{29}$ This classification has its primer in the insight gained from the early use of intracoronary imaging (ICI) in $\mathrm{SCAD}^{27} 28$ and it has a correspondence with the pathological substrates depicted with ICI (figure 2). Nevertheless, the angiographic aspect is sometimes too ambiguous to make a firm diagnosis of SCAD, requiring confirmation through ICI or by assessing vessel restoration in repeat angiography. Considering all the available resources and its appropriate use is key to refine diagnosis and avoid overlooking SCAD, which would crucially change patient management and prognosis.

The orientation provided in this regard by the position papers recently published ${ }^{13} 14$ is vague and perhaps too simple for practical application. Adapting the existing guidance and available evidence, we here propose an up-todate diagnostic algorithm intended to maximise the role of coronary angiography for SCAD diagnosis (figure 3).

\section{Coronary angiography}

Classically, SCAD was recognisable as a double lumen or 'flap', result of an open communication of the true lumen with the dissected plane (false lumen). This corresponds to angiotype 1 , in which multiple lumens, a flap, or wall contrast-staining may be seen (figure 2, column 1). Although being the classic finding, angiotype 1 only accounts for $26 \%-43 \%$ of the cases in SCAD series. ${ }^{689}$ This pattern, when clearly identified, is considered diagnostic itself (figure 3).

Differently, when the dissection plane (false lumen) encompasses a contained intramural haematoma that does not allow contrast to enter in it (with or 


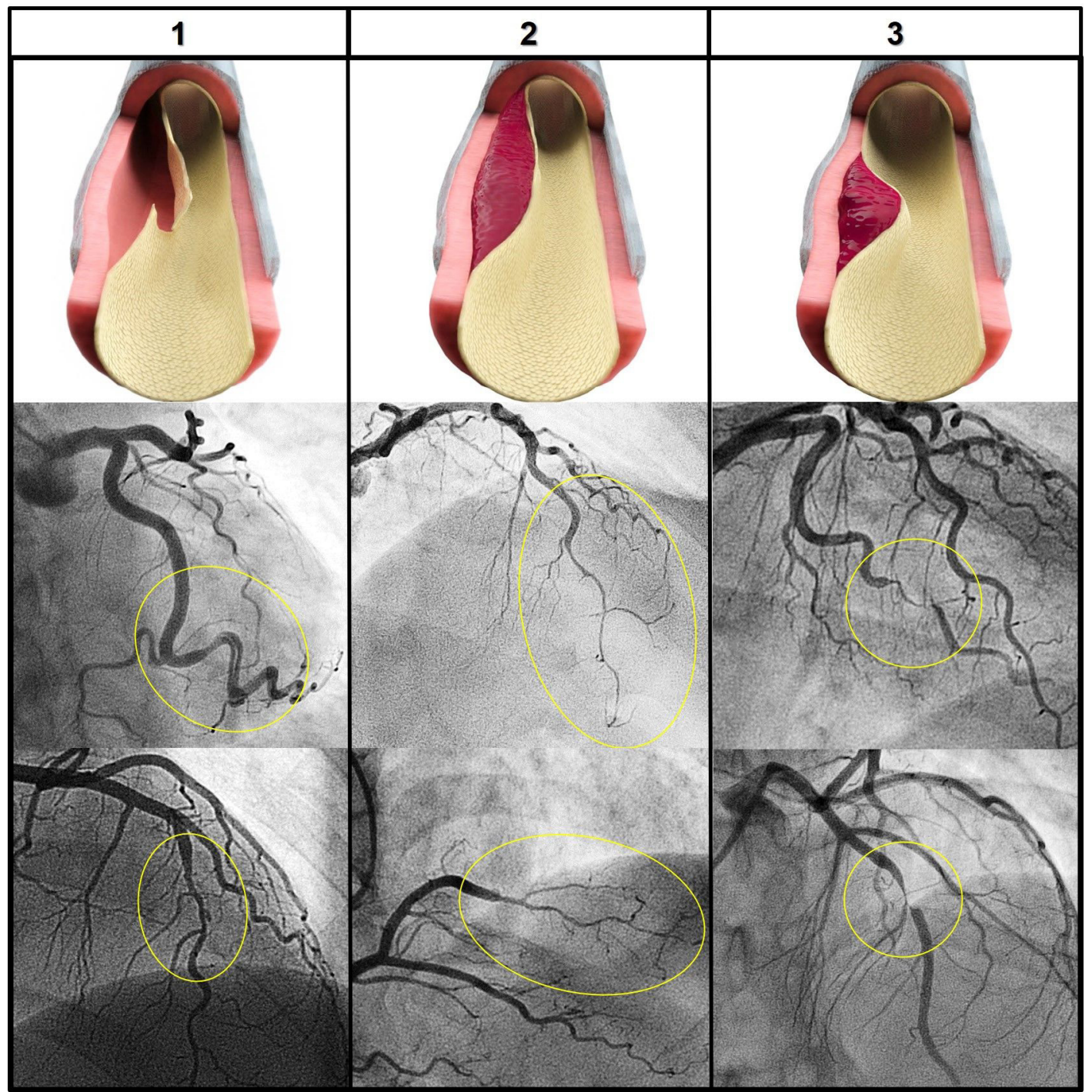

Figure 2 Angiographic presentations of spontaneous coronary artery dissection and corresponding anatomopathological features. First row describes the anatomical lesions behind each angiographic lesion (circles). Column 1 corresponds to angiotype 1: double lumen or luminal flap. Column 2 corresponds to angiotype 2: long smooth tapering. Column 3 corresponds to angiotype 3: focal stenosis.

without intimal tear), angiography only reveals vessel narrowing or tapering. This narrowing is characteristically long with smooth borders, usually starting and ending at a bifurcation, with or without distal recovery of vessel's diameter; this corresponds to angiotype 2 (figure 2, column 2). This pattern is the most common according to SCAD series reporting this feature, accounting for $55 \%-78 \%$ of the cases. ${ }^{69}$ Angiotype 2 , although not considered pathognomonic, it can be diagnostic when typical and accompanied with other features. We propose a criterion whereby the combination of a clinical profile of a relatively young $(<60$ years) female with low cardiovascular risk burden (non-diabetic and $\leq 1$ cardiovascular risk factor) plus either a recent pregnancy ( $<1$ year) or an angiographic appearance of severe tortuosity would be sufficient to support SCAD diagnosis in the presence of an angiotype 2 (figure 3 ). Some cases present both angiotype
2 and 1 in the same vessel (online supplementary video 1 , material 1). For these cases, diagnosis should be even more clear than when only one of the two patterns is recognisable.

Finally, angiotype 3 is the ambiguous pattern and is the least common angiographic presentation, although very likely is under-represented (misdiagnosed). It corresponds to a discrete, not propagated intramural haematoma that gives the appearance of a focal lesion, sometimes mimicking atherosclerosis (figure 2, column $3)$. Its ambiguity makes diagnostic confirmation mandatory.

When diagnosing SCAD solely on grounds of the first angiography (angiotype 1 or 2), (figure 3) one should consider the following caveats:

- Prior to consider SCAD, it is important to have excluded vasospasm by previous nitroglycerine administration. 


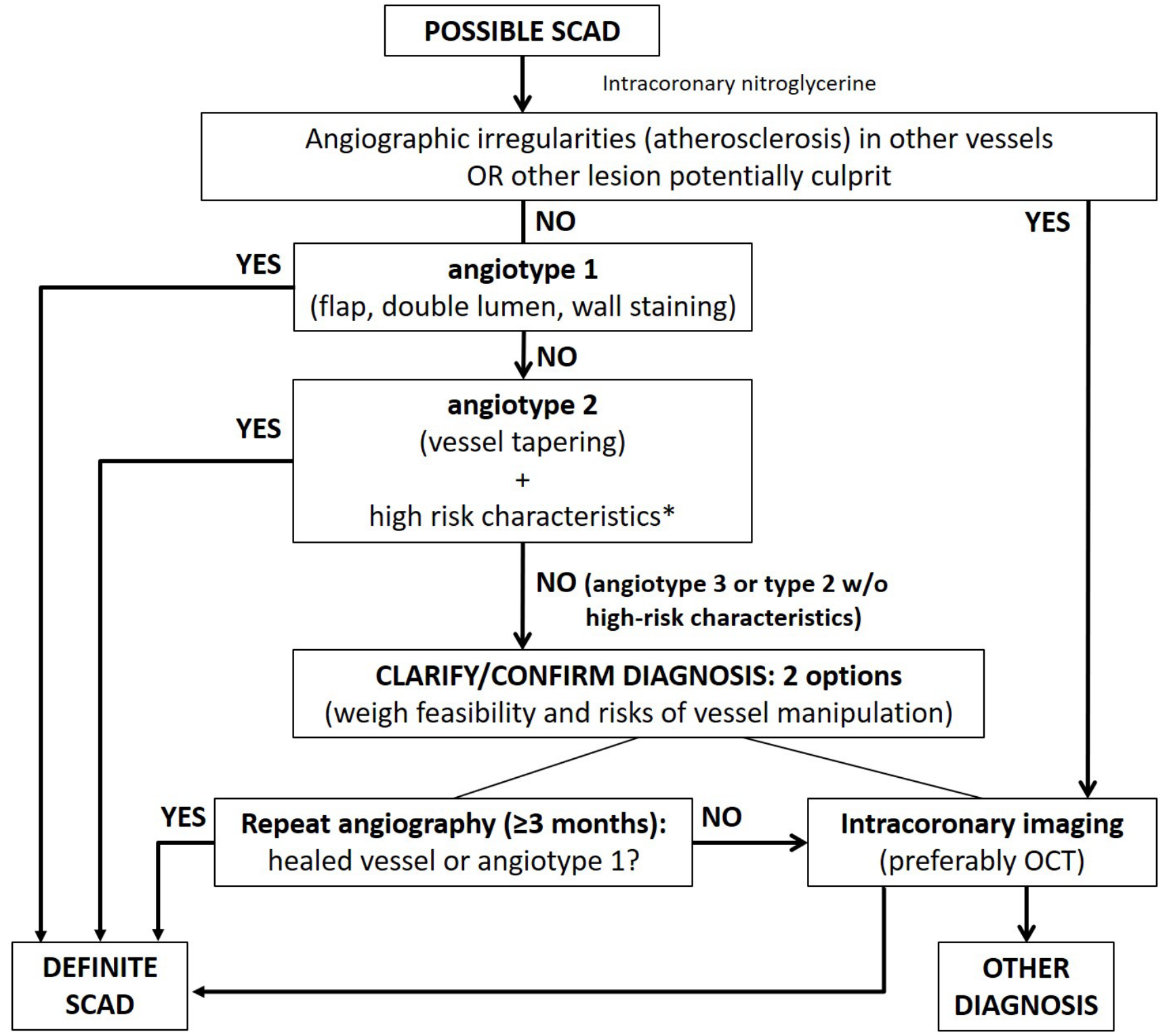

*Typical clinical profile (woman <60 years, non-diabetic, $\leq 1 \mathrm{CVRF}$ ) plus one of the following:

(i) recent pregnancy (<1 year)

(ii) angiographic tortuosity: $\geq 3$ consecutive curvatures of $90^{\circ}$ to $180^{\circ}$ measured at end-diastole in a major epicardial coronary artery $\geq 2 \mathrm{~mm}$ in diameter (adapted from Eleid et $\mathrm{al}^{2}$ )

Figure 3 Flowchart diagram for the diagnosis of spontaneous coronary artery dissection (SCAD). CVRF, cardiovascular risk factor; $\mathrm{ICl}$, intracoronary imaging.

- Sometimes it is not possible to clearly distinguish a pattern due to flow impairment or when the dissected vessel has a small calibre, in such cases diagnostic confirmation is pertinent (management as angiotype $3)$.

- The alleged SCAD lesion must be a culprit lesion. Otherwise, chronic incidental findings of these patterns or the presence of a remote culprit lesion would preclude relying on angiographic SCAD diagnosis. Furthermore, as per the current knowledge of this entity, chronic
SCAD is not a reliable diagnosis because one cannot ascertain the exact aetiology of a flap (ie, it could be an unhealed SCAD, but also a recanalised occlusion, dissection originated from a plaque rupture, etc).

- The presence of irregularities suggesting atherosclerosis in other vessels (online supplementary video 2, material 1) or non-dissected segments should prompt further assessment of the lesion, if feasible, with ICI to further clarify the aetiology and exclude atherosclerosis-related dissection. 


\section{Diagnosis confirmation through surveillance angiography}

When diagnostic confirmation is required, there are two possibilities (figure 3): (i) to gain further insight of the angiographic finding through ICI or (ii) to evaluate lesion's evolutive behaviour overtime with scheduled surveillance angiography. One should choose the most appropriate option according to each particular SCAD scenario. Scheduled surveillance angiography should be favoured over ICI in stable patients in which the operator does not intend to treat the affected vessel, and when there is a low likelihood of success of ICI due to proximal tortuosity and/or distal or small vessel diameter. As mentioned before, SCAD affects more frequently mid and distal segments, which discourages and sometimes precludes the use of ICI.

Spontaneously dissected coronary arteries tend to spontaneously heal-a pillar for the conservative attitude in SCAD management-and thus, if the initial angiographic finding correspond to SCAD, an evolutive change is expected in repeated studies (online supplementary figure B, material 1). In a study by Saw et al, all patients that were scheduled for surveillance angiographic follow-up after 4 weeks showed some degree of vessel healing. ${ }^{36}$ Ad integrum restoration or conversion to angiotype 1 support a definite SCAD diagnosis, whereas other findings are less conclusive and may require further investigation with ICI to disclose the underlying aetiology or perhaps to repeat angiography after a longer period (figure 3 ).

There is no definite time lapse for scheduling the surveillance study, but some authors have suggested 1 month. ${ }^{14}$ From our experience, SCAD healing process may last beyond 1 month in a number of SCAD cases (online supplementary figure $\mathrm{B}$, material 1 ). Therefore, in order to optimise the role of surveillance angiography for detecting significant changes, as well as to minimise the risk of iatrogenic damage, ${ }^{79}$ it is reasonable to allow a longer time lapse for artery healing ( $\sim 3$ months). Nonetheless, this can be tailored according to the size of the lesion that is, small haematoma may reabsorb within 4 weeks whereas a largest one may take up to several months.

\section{Diagnostic confirmation with intracoronary imaging}

ICI reveals such unique and genuine findings of SCAD at the vessel's wall that it may be acknowledged as the gold standard diagnostic investigation. ${ }^{27}$ However, its invasiveness, increased costs and availability limits its use. ${ }^{20}$ Special consideration should be paid to the potential harms entailed: wiring, contrast injection and ICI catheter may jeopardise vessel patency or provoke a superimposed iatrogenic dissection. ${ }^{79}$ Nonetheless, the potential of ICI to clarify uncertain findings makes it central when a definite diagnosis is pursued.

ICI should be performed essentially in the following situations: (i) when percutaneous coronary intervention (PCI) is required (diagnostic confirmation +procedural guidance) and (ii) for unclear angiographic lesions when a therapeutic decision depends on ICI findings (eg, not treating if it is SCAD), especially in proximal and amenable type 3 and dubious type 2 lesions. It should also be encouraged

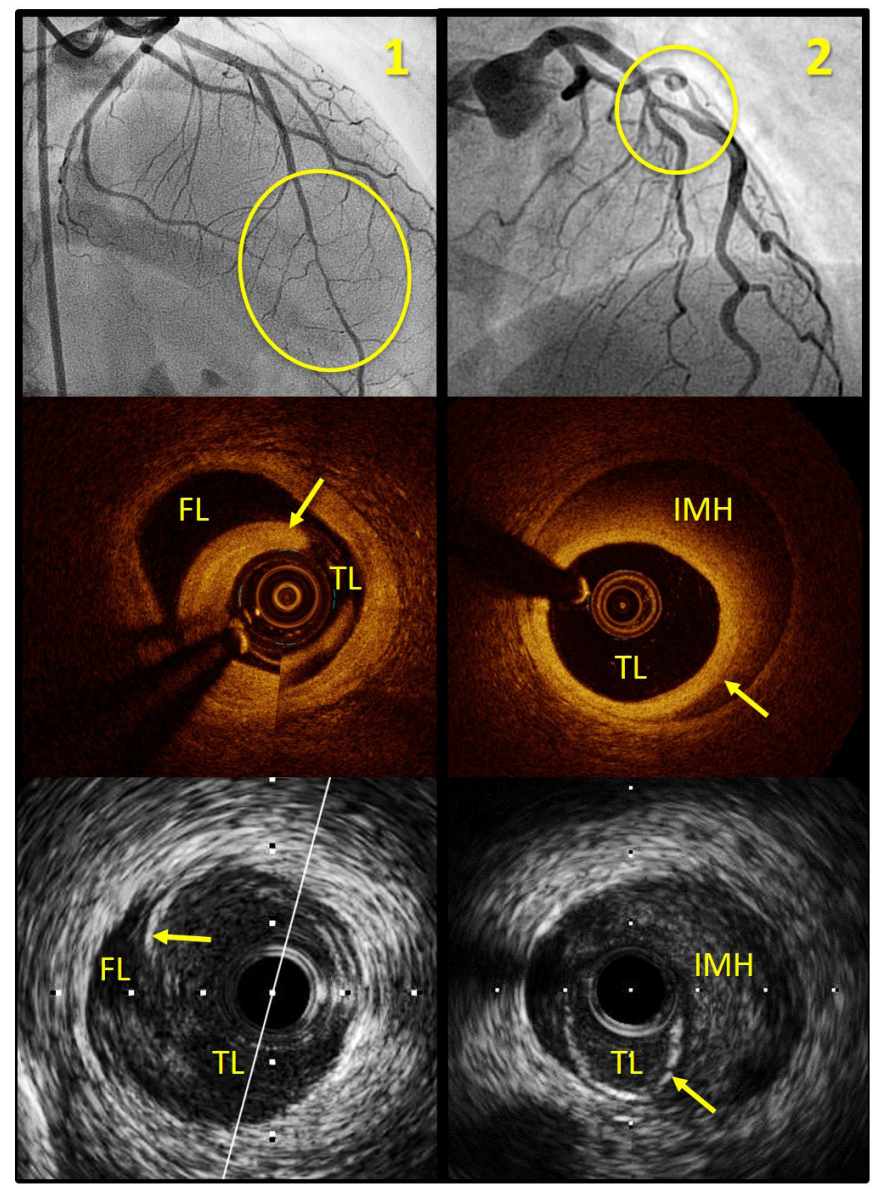

Figure 4 Spontaneous coronary artery dissection (SCAD) hallmarks in intracoronary imaging. FL, false lumen; IMH, intramural haematoma; TL, true lumen. Arrow indicates myoendothelial lamina (intimomedial flap).

for patients with clinical suspicion and repeated episodes of ACS that have not been previously diagnosed and have been treated as atherosclerotic disease.

The hallmark of SCAD that is revealed with ICI is the myoendothelial lamina (intimomedial flap). This can present as a clear double lumen (figure 4, case 1) or as a contained intramural haematoma (figure 4, case 2). Compared with intravascular ultrasound (IVUS), optical coherence tomography (OCT) has a superior spatial resolution and provides a finer depiction of vessel's wall, which implies a greater sensitivity to detect the extension of the dissection and subtle intimal tears. ${ }^{28}$ In counterpart, OCT has a limited in-depth visualisation, especially noted in the presence of large false lumen or intramural haematoma. Moreover, OCT requires a vigorous contrast injection, which carries an additional risk of hydraulic trauma. IVUS does not depend on contrast filling, which may be an advantage for assessing vessels in which anterograde flow is impaired.

Once diagnosis is established, repeating ICI for surveillance purposes should be reserved for follow-up of PCI or dubious symptoms in conservatively managed patients. In any case, it is sensible to postpone any vessel manipulation after the acute phase to allow vessel's wall stabilisation 
and avoid interfering with the ongoing vascular healing process. $^{81}$

\section{Diagnosis in occlusive SCAD}

Severe flow impairment (thrombolysis in myocardial infarction (TIMI) 0-1) generally impedes making an angiography-based diagnosis. For these cases, the diagnostic approach may overlap with the management strategy. If the vessel is small and distal, one may opt for an expectant attitude and scheduling a surveillance angiography. Conversely, if the dissected segment is amenable for intervention, an initial attempt to partially restore flow by wiring may be enough to unveil angiographic features that may support diagnosis. If that turns fruitless, ICI may be used. Overall, the risks and benefits of instrumenting a dissected vessel must be weighed. As mentioned above, in cases where PCI is clearly required (eg, proximal-mid LAD occluded), ICI is useful to both confirm diagnosis and guide intervention.

\section{Computed tomography coronary angiography}

CT coronary angiography, although potentially capable of diagnosing some cases, ${ }^{82}$ does not seem a reliable tool for making a definitive diagnosis nor ruling out SCAD. ${ }^{83} 84$ Its low spatial resolution to study vessel's wall coupled with the fact that SCAD often presents in distal segments limits its application. However, this imaging modality may have a role in some scenarios: (i) follow-up of conservatively managed patients with proximal vessel involvement ${ }^{8586}$; (ii) monitoring of untreated post-PCI proximally-propagated dissections; (iii) follow-up of complex PCI procedures or those involving coronary ostia; and (iv) follow-up of patients treated with bioresorbable stents. ${ }^{87}$

- Anatomically, SCAD has a preference for mid to distal coronary segments, and left anterior descending is the most commonly vessel involved, followed by circumflex and right coronary arteries. Multivessel affection is rare.

- Angiographic features, along with the clinical profile, are usually enough to support the diagnosis of SCAD.

- In dubious scenarios, use of intracoronary imaging may disclose the pathological substrate. Alternatively, repeat angiography can be performed to document healing and confirm the diagnosis of SCAD.

- The advantages of intracoronary imaging should be carefully weighed against the potential harm of instrumenting a dissected vessel.

\section{ACUTE MANAGEMENT}

In contrast to the common atherosclerotic ACS, it is now widely acknowledged that conservative management is the preferred strategy for patients with SCAD whenever clinically possible (ie, preserved epicardial flow and clinical stability); ${ }^{13} 147888$ yet, no direct randomised comparison between revascularisation and conservative strategy has been undertaken.

The preference of conservative management resides in the natural history of spontaneous healing in $\mathrm{SCAD}^{36}$ coupled with the challenging scenario that the dissected coronary vessels means for PCI (fragile vessels, often mid-distal location) and the consequent high rates of failure and/or complications. ${ }^{31120}$ As a matter of fact, conservative management is generally associated with favourable outcomes and low rates of early urgent revascularisation $(<10 \%),{ }^{20-22} 35$ whereas revascularisation subgroups have consistently shown poor clinical outcomes. ${ }^{13113688-90}$ As stated above, this are not randomised comparisons and consequently there is a potential confusion bias. In fact, patients selected for revascularisation present from the beginning with high-risk prognostic-modifying features such as impaired TIMI flow at presentation, extensive ischaemia and haemodynamic instability. ${ }^{311}$

The real-world practice reflected in the series published in the last years shows revascularisation rates varying from $12 \%$ to $56 \% .^{1-46-9}$ However, the paradigm shift appears to be taking place, as a recent national temporal trend analysis has revealed a decrease in in-hospital mortality in SCAD patients parallel to a decline in PCI rates. ${ }^{90}$ Nevertheless, in some cases, SCAD leads to extensive ongoing myocardial ischaemia that jeopardises a significant amount of myocardium, particularly where SCAD affects more proximal coronary segments. These patients may benefit from revascularisation with PCI or emergent coronary artery bypass graft surgery (CABG).

PCI is usually attempted as the first revascularisation method given its readiness and less invasiveness, whereas CABG is generally deemed auxiliary or reserved for cases where PCI is deemed too complex. CABG has shown acceptable clinical outcome in SCAD series, though graft failure has been reported as high as two thirds in the follow-up, likely consequence of the spontaneous healing of the native vessel. ${ }^{311} \mathrm{~A}$ firm recommendation cannot be issued for selecting patients with $\mathrm{SCAD}$ for $\mathrm{CABG}$, but rather this should be dictated by site expertise.

Considering all these aspects, a simplified practical algorithm for decision-making in the acute management of SCAD is proposed in figure 5 . This algorithm primarily considers patient clinical status for decision-making, but also encompasses anatomical features such as size of the dissected vessel and degree of flow impairment.

\section{Clinically driven repeat angiography}

After either conservative or revascularisation management, it is imperative to monitor the patient closely for early detection of ischaemic relapses. Recurrent atypical chest pain episodes are common after the SCAD event and can last long after discharge in some patients. ${ }^{21} 9192$ After-event chest pain is frequently not accompanied by new angiographic findings. Thus, when returning a SCAD patient to the catheterisation laboratory for chest pain, one should consider the possibility of spurious linking between symptoms and angiographic findings, but also bear in mind the dynamic behaviour of SCAD lesions. Precisely, a particular phenomenon that may occur in SCAD is the delayed longitudinal propagation of the dissection plane to a different segment or vessel. In the event of a relapse with objective ischaemia and worsening clinical status, the decision to 


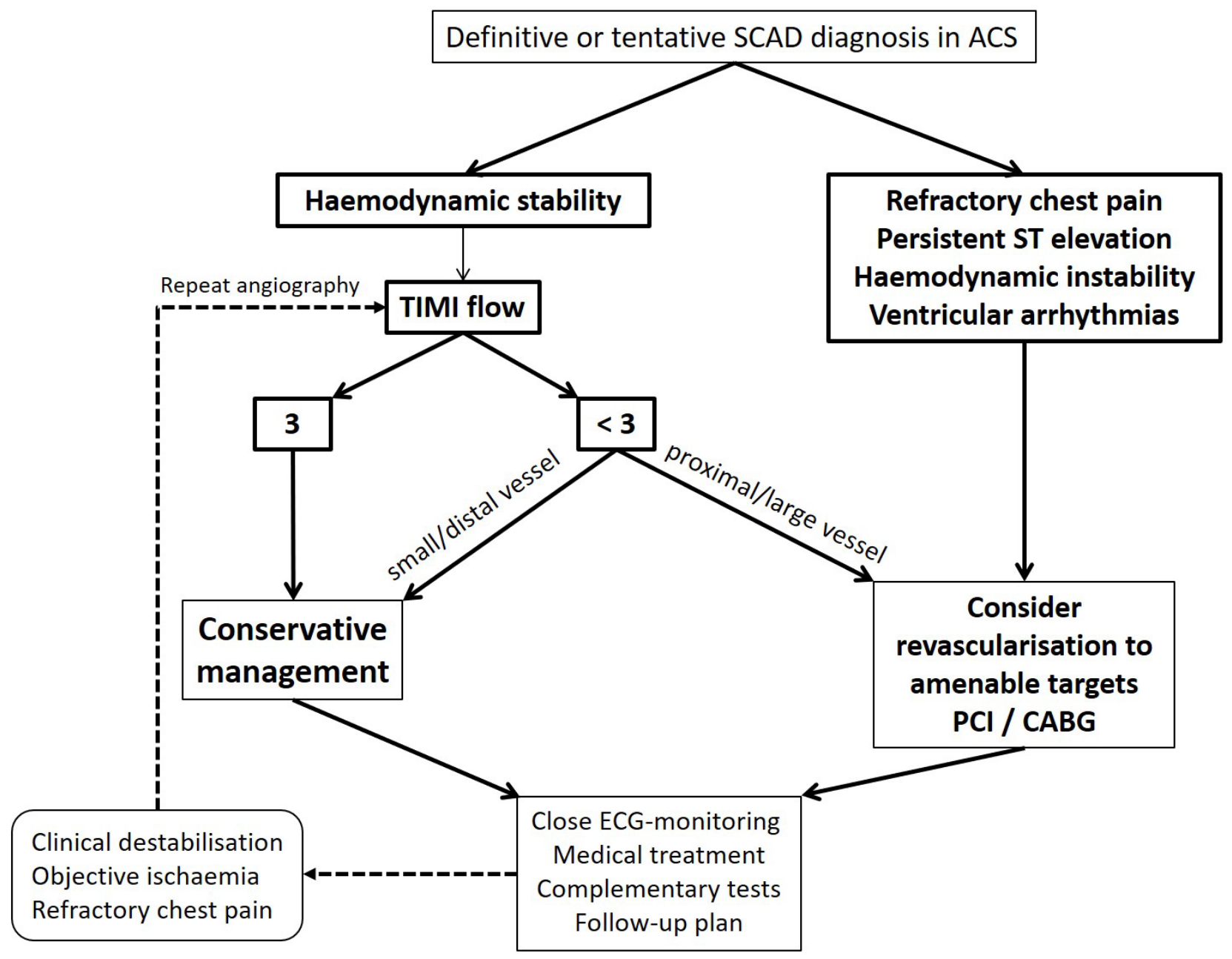

Figure 5 Flowchart diagram for acute management of SCAD. CABG, coronary artery bypass graft surgery; PCl. percutaneous coronary intervention; SCAD, spontaneous coronary artery dissection; TIMI, thrombolysis in myocardial infarction.

revascularise should not be very different to that recommended for initial presentation, particularly avoiding PCI if thrombolysis in myocardial infarction (TIMI) coronary flow is preserved (figure 5).

\section{$\mathrm{PCl}$ challenges and strategies}

PCI is risky and technically challenging in the setting of $\mathrm{SCAD}$, and there is not a preferred strategy that has shown superior. See box 1 for caveats and suggestions regarding PCI in SCAD. Note that the general approach applies for conservative management too (ie, diagnostic procedures). Given the propensity for iatrogenic damage that coronary arteries have in patients with $\mathrm{SCAD},{ }^{79}$ a meticulous technique is required in all steps.

Balloon-only angioplasty is usually attempted upfront to restore flow; however, it is unlikely to achieve a durable result as a sole treatment because the dynamic behaviour of this entity may lead to early vessel reocclusion. Moreover, any dilatation does carry a risk of dissection propagation, especially in focal compressing haematoma. Lettieri et al reported 7 of 51 patients with SCAD treated with PCI received balloon-only angioplasty, though they did not report the specific outcome for this group of patients. ${ }^{3}$ The use of a cutting or scoring balloon to fenestrate the intimomedial flap in order to decompress intramural haematomas is an interesting concept, though not free of risk. A few isolated published cases have reported a favourable outcome $^{9394}$; however, this kind of evidence is susceptible to selection and/or publication bias.

Stents prevent vessel reocclusion and are the standard of treatment in SCAD PCI. However, instead of pursuing a complete coverage of the diseased segment-standard practice in atherosclerotic disease - the main objective of stenting should be to relieve the critical stenosis and recover vessel's patency. Thus, post-PCI residual lesions should be approached conservatively, and only treat them if clearly severe or causing clinical ischaemia.

Both drug-eluting or bare-metal stents have been indistinctly used in SCAD. Both devices were compared in a recent retrospective study based on a large international SCAD series $(n=238)$. A total of 108 patients with SCAD 
Box 1 Technical considerations for percutaneous coronary intervention in spontaneous coronary artery dissection

General approach:

- Careful catheter manipulation and coronary engagement to avoid iatrogenic dissection

Low threshold for femoral access

- Gentle contrast injections

Approach for PCl:

- Low threshold for wiring side branches beforehand Most operators prefer non-hydrophilic wires (to prevent from further dissecting and improve tactile feedback)

- If TIMI 0 , non-hydrophilic wire \pm use small-size balloon to try to restore vessel flow

- Intracoronary imaging guidance for distinguishing true and false lumens and assess accurately vessel dimension is strongly recommended

- Do not aim always for a 1:1 vessel:stent sizing, especially in the presence of compressing haematoma or big false lumen with vessel enlargement

- Gentle stent dilatations; do not target optimal strut apposition; best if guided by ICl

- The main goal is to restore TIMI flow 2-3 by stenting preferably the most proximal segment (avoid sealing all the dissected segments)

For highly-compressive contained intramural haematoma consider

alternative approaches:

- Cutting balloon \pm stent to fenestrate the intimomedial flap

- Self-expandable stent to accommodate subsequent vessel remodeling

- Staged postdilatation to allow haematoma resorption/vessel restoration

received PCI (45\%), 48 treated with drug-eluting stents and 60 with bare-metal stents. After a median follow-up time of 3.3 years (IQR 1.5-7.6), there was a non-significant trend of lower MACE occurrence in the drug-eluting stents group ( $17 \%$ vs $31 \%, \mathrm{p}=0.11)$, mainly driven by target-vessel revascularisation ( $4 \%$ vs $18 \%, \mathrm{p}=0.08$ ). The study was underpowered but the findings were clinically important. ${ }^{95}$

Off-label use of bioresorbable devices in this setting was proposed as an appealing alternative to metallic stents for these young and otherwise healthy patients. ${ }^{879-98}$ However, the substandard performance of the polylactic acid scaffold Absorb in the treatment of atherosclerosis ${ }^{99}{ }^{100}$ which not necessarily translates into the same outcome for SCAD, led to the manufacturer to stop the production of this device, and therefore is no longer available. Nevertheless, the concept remains attractive for these patients, and future improved bioresorbable platforms overcoming limitations of the primer device will surely be tested for this purpose. ${ }^{101}$

For cases in which intramural haematoma appears highly compressive, a hybrid approach with cutting balloon prior to stent implantation could be useful to evacuate the contained haematoma and prevent late malapposition after the haematoma is resorbed. ${ }^{102}$ Alternatively, others have proposed staging stent optimisation with postdilatation after certain time, ${ }^{103}$ or the use of self-expanding platforms, that may accommodate to haematoma displacement and vessel remodelling and ultimately achieve a better late apposition in these cases. ${ }^{104}$

Stent malapposition or underdeployment are frequent findings in routine surveillance angiographies or autopsy. ${ }^{105106}$ However, since an increased incidence of stent thrombosis in the setting of SCAD has not been confirmed, the clinical implication of these findings remains uncertain.

ICI guidance is paramount for ensuring true lumen access and avoiding stents deployed in the false lumen, ${ }^{107}$ which causes obliteration of the true lumen and pathological remodelling of the vessel. ${ }^{106} \mathrm{ICI}$ also allows a fine depiction of the lesion and its extension, accurate dimensioning of the vessel and proper stent selection. In this regard, IVUS may be better for accurately sizing of the vessel and provide a more detailed characterisation of the false lumen, especially in cases where the true lumen is severely distorted and contrast filling is insufficient for OCT. ${ }^{20}$

Dissection propagation, another issue derived from PCI in SCAD, frequently leads to further stenting of a longer artery segment. This can occur either by simple wiring or following dilatation that provokes blood displacement through the false lumen plane. Avoiding a constant target of 1:1 vessel:stent and optimal apposition, as well as being gentle with dilatation pressure, may help to prevent this complication.

Whenever clinically possible, conservative management is the preferred strategy in SCAD.

- Because SCAD is a treacherous scenario for percutaneous coronary intervention, every precaution must be taken to prevent specific complications (see Box 1).

\section{CONVALESCENCE MANAGEMENT}

Special considerations for management of patients with SCAD after clinical stabilisation are summarised in Box 2. In-hospital management is similar to that of any other patient with ACS, with extra consideration regarding the appearance of ischaemic relapses (including late propagation). Most cases can be safely discharged after a few days of convalescence, yet this should be individualised to each case. Ventricular function should be monitored during hospitalisation and later after discharge since left ventricular systolic impairment at baseline has shown to improve significantly in the short term. ${ }^{58}$ This has implications for tailoring medical treatment and, especially, for appropriately indicating primary prevention of sudden cardiac death in those patients with severe ventricular disfunction. ${ }^{59}$ If left ventricular function is severely depressed, until reassessment, the role of wearable defibrillators for this relatively young population is appealing.

\section{Pharmacologic treatments}

No firm recommendations can be made regarding medical treatment in SCAD given the lack of evidence-based therapies and the current limited knowledge about the pathophysiological mechanisms underlying this condition. Potential risks, adverse effects and theoretical benefits should be 
Box 2 Summary of recommendations for spontaneous coronary artery dissection (SCAD) survivors

Reassessment of left ventricular function (life vest if necessary until then)

Differential diagnosis of chest pain after SCAD should distinguish non-ischaemic chest pain from less common serious causes: late propagation (days, weeks) or de novo SCAD recurrence (months, years), which may occur regardless of the treatment received Medications:

- Tailor heart failure therapy in accordance with left ventricular function that should be monitored to evaluate recovery

- Dual antiplatelet therapy only for patients having stents implanted

- Consider long-term beta-blocker if well tolerated (nebivolol for coexisting migraine)

- Statins only for dyslipidaemia or evidence of atherosclerosis

- For patients with fibromuscular dysplasia: aspirin, beta-blocker and ACE inhibitor or ARB

Systematic screening of extracoronary arteriopathy, preferably with a magnetic resonance angiography-based protocol Genetic testing only if a connective tissue syndrome or familiar

aggregation is suspected

Cardiac rehabilitation programmes and mental health assessment

are appropriate Discharge counselling:

- Control of cardiovascular risk factors, with special emphasis in smoking and blood pressure

- Encourage physical activity but avoid extenuating or isometric exertion (weight lifting)

- Avoid recognisable emotional stressors

- Preferential use of non-hormonal over hormonal therapies

- Eventual pregnancies should be closely monitored by a multidisciplinary team

weighed when deciding the pharmacologic treatment for patients with.

While some concerns have been raised regarding the potential deleterious effect of antithrombotic therapy in enhancing intramural bleeding and facilitating haematoma propagation, ${ }^{13} 1422$ no evidence supports this theoretical hazard. It is relatively straightforward that in those receiving stents dual antiplatelet therapy should be maintained for 12 months in keeping with current guidelines. ${ }^{108}$ However, for conservatively managed patients no benefit is expected. Most common practice is to maintain lifelong low-dose aspirin and to stop the second antiplatelet agent early after the acute event. ${ }^{20}{ }^{22}$ We do encourage to stop the second antiplatelet agent soon after diagnosis of SCAD has been made. Heparin is given as a standard for ACS, but since there is no foreseeable benefit for this condition and there is a theoretical potential harm, early discontinuation is also encouraged. ${ }^{1314}$

In the presence of any intolerance or bleeding (beware of uterine bleeding), even stopping aspirin should be considered given the lack of evidence for the SCAD population. Uterine bleeding can be a problem in these patients, and cardiologists may not be well acquainted with it. Stopping the antithrombotic agent is generally possible; though, if not (eg, stented SCAD), a high-dose levonorgestrel intrauterine coil can be prescribed to reduce significant bleeding. ${ }^{14}$

Beta-blockers, ACE inhibitors, angiotensin and mineralocorticoid receptor antagonists should be administrated according to ACS guidelines. ${ }^{109} 110$ However, given the trend towards prompt recovery of left ventricular ejection fraction, ${ }^{58}$ the duration of these medications should be appropriately tailored. On the other hand, data from a multivariate analysis in a large SCAD cohort in Canada suggest a long-term benefit in maintaining beta-blockers for preventing recurrences, ${ }^{9}$ though these data still need to be reproduced in other cohorts. Their antiadrenergic effect (to buffer physical/emotional stressors) or the reduction of arterial wall shear stress are plausible mechanisms for this alleged benefit. Renin-angiotensin antagonists should be used with caution in women in childbearing age given their potential teratogenicity. Statins are not considered beneficial in these patients; what is more, a previous observation suggested potential harm. ${ }^{111}$ Statins should only be prescribed if there is evidence of atherosclerosis or hyperlipidaemia, as commonly for primary or primordial prevention for cardiovascular disease.

As previously mentioned, chest pain with non-demonstrable ischaemia may appear, persist or be cyclic, even related to menstruation (catamenial chest pain). ${ }^{219192}$ This can result very disconcerting and frustrating for patients. A trial switching beta-blockers for nitrates, calcium channel blockers or even more modern antianginal drugs can be attempted. For refractory catamenial chest pain in premenstrual women, local or systemic hormonal contraception to stabilise the menstrual cycle may be considered after failure of antianginal drugs. ${ }^{14} 21$

Regarding hormonal treatment in patients with SCAD, no compelling evidence conveys contraindication of these therapies. However, it seems reasonable to avoid them if an alternative is available (contraception barrier methods, local or non-hormonal treatment for menopausal symptoms), as well as using progestin-only-based methods over the combination with oestrogen.

\section{Screening for extracoronary arteriopathy}

Although no clinical benefit has been yet demonstrated for screening extracoronary arteriopathy in patients with $\mathrm{SCAD}$, it is recommended by experts in both SCAD and FMD. ${ }^{20} 223839112$ The main reasons are (i) high prevalence of FMD in some of the largest SCAD studies were systematic investigation was conducted ${ }^{9}$; ; (ii) twofold higher prevalence of intracranial aneurysms in patients with FMD compared with general population ${ }^{113}$; and (iii) potential benefit from interventional treatments in patients with significant stenosis due to FMD: $38 \%$ of the patients in the US FMD registry underwent an intervention. ${ }^{42}$

Among the array of available imaging modalities to screen extracoronary arteriopathy (figure 1), the use of magnetic resonance angiography (MRA) as a standard protocolised investigation for patients with SCAD is a sensible option. Its non-invasiveness and absence of ionising radiation are of special importance for a screening technique applied in 
relatively young patients with a longer potential lifespan and more prone to undergo additional imaging testing. ${ }^{4114115}$ Despite the sensitivity of MRA may not be as high as CT, it has enough spatial resolution for detecting clinically relevant findings that would benefit of treatment or further surveillance. ${ }^{116-118}$ Plus, MRA is endorsed as a diagnostic technique by expert consensus on FMD from Europe and the USA. ${ }^{38} 39$ The acquisition protocol may vary but should always include abdominal-femoral and cervical-cranial arterial beds since these are the most affected territories. ${ }^{40}$

Should vascular abnormalities or FMD are found, a multidisciplinary approach is pertinent. Appropriate referrals according to clinical manifestations must be arranged with neurologists (history of cerebrovascular events, migraines and tinnitus +cervical-cranial FMD), nephrologists (hypertension +renal FMD) and vascular surgeons (for considering interventions). Intracranial aneurisms should be managed following corresponding guidance. ${ }^{117}$

From a medical viewpoint, general principles of cardiovascular health and secondary prevention apply similarly to the patient with FMD, with special attention to blood pressure control and smoking cessation. The latter is associated with an aggressive course of the disease ${ }^{119}$ Although there is no evidence-based pharmacological treatment, an antiplatelet drug and antihypertensive therapy is recommended. ${ }^{38}{ }^{39}$ For the reasons discussed above, the first agent to use would be a beta-blocker, followed by an ACE inhibitor or ARB (deemed potentially beneficial for their effects in the transforming growth factor-beta pathway). Additionally, liposoluble beta-blockers as nebivolol may also be useful for concomitant treatment of migraine in these patients. More specific aspects regarding management of FMD are outside the focus of this paper and can be reviewed elsewhere. ${ }^{38} 39120$

\section{Genetic screening}

As discussed in a previous section, genetic testing has a low yield, and thus, routine screening is not recommended. However, it is advised to conduct a three-generation pedigree and an anamnesis and examination directed to seek features such as those pertaining to Marfan or Ehlers-Danlos syndromes. ${ }^{14}$ Screening first-degree family members is not indicated unless an heritable disorder has been diagnosed in the proband.

\section{Cardiac rehabilitation and psychological disorders}

Patients generally experience the SCAD event as highly stressful and are rendered fearful thereafter. Cardiac rehabilitation is especially important for these young otherwise healthy patients, rather sensitive to suffer psychological repercussions after the event. ${ }^{18}{ }^{19}$ Cardiac rehabilitation has shown to be safe an effective to improve exercise capacity, recurrent chest pain and mental health. ${ }^{121}{ }^{122}$ A module of 3-6 months is reasonable after the event. Moreover, even patients with history of SCAD that did not undergo cardiac rehabilitation at that time may benefit from being included at present, especially if they show apprehension towards their cardiac condition. Mental health disorders such as anxiety, depression or post-traumatic stress disorder should be actively addressed and appropriately referred to a specialist if necessary.

\section{Discharge counselling}

In addition to joining cardiac rehabilitation programme, SCAD survivors must receive appropriate counselling before discharge to understand that theirs is a condition different to conventional ischaemic heart disease, and therefore not every recommendation given for the latter is equally valid for them. They should nonetheless be encouraged to follow a healthy lifestyle, particularly quitting smoking and controlling blood pressure.

Some concerns have been raised regarding pregnancy after SCAD and some authors recommend against or deter patients from becoming pregnant. ${ }^{20} 22$ Nevertheless, the evidence is very scarce, with only one small observation reporting one P-SCAD in eight women with history of SCAD (four were P-SCAD). ${ }^{123}$ The paucity of data prevents from systematically discouraging pregnancy in SCAD survivors. In any case, it is reasonable to address these pregnancies as of high risk and provide close surveillance and an individual assessment by a multidisciplinary team.

- Available evidence on pharmacologic intervention in SCAD is limited

Screening extracoronary arteriopathy appears reasonable for ruling out clinically relevant extracoronary arteriopathy.

- Cardiac rehabilitation programs are beneficial and should be offered.

- SCAD survivors may suffer disinformation and helplessness. Social and professional networks are potential tools to address these issues. A dedicated and personalised counselling is recommended.

\section{CLINICAL OUTCOMES AND PROGNOSIS}

In-hospital mortality is reported low, $0 \%$ in many series and no higher than $3 \% .^{20}$ In-hospital MACE was reported in $8.8 \%$ of the recently presented Canadian registry $(n=750)$, with about half of them being reinfarctions. ${ }^{35}$ P-SCAD, TIMI flow 0-1, proximal dissections and STEMI are characteristics that associate a worse in-hospital outcome. ${ }^{31135}$

Reported long-term MACE of patients with SCAD vary from $6 \%$ to $28 \%$ in the different series, and this is not explained by different follow-up times. ${ }^{467911}$ Long-term mortality rate is very low across the series $(0 \%-5 \%$ with follow-up medians of 3-6 years). ${ }^{3469}$ Long-term MACE are mainly driven by recurrent SCAD and MI in these patients, and revascularisation does not prevent it, nor prevents late target vessel revascularisation. ${ }^{1189}$ The wide variability observed in the rates of MACE is likely due to a heterogenous criteria for adjudicating SCAD recurrence. The latter should be distinguished from late propagation, which is the early relapse that tends to occur within first days (weeks the latest) after the index event. A true recurrence, also called de novo recurrence, is a new event occurring in the mid to long term and consists in a new SCAD that appears to invariably involve a distinct coronary segment (and vessel in most cases) from the initially dissected and subsequently healed 
one. ${ }^{124}$ True or de novo recurrences occurred in $10.4 \%$ at a median of 3.1 years in the largest series published. ${ }^{9}$

To date, apart from coronary tortuosity, ${ }^{2}$ no other predictors for recurrence have been identified and, as abovementioned, no evidence-based therapies effectively modify prognosis. However, for the time being, the recommendations presented in this review, which are essentially in keeping with those from expert consensus from Europe and North America, ${ }^{13} 14$ are considered the best standard of care for patients with SCAD, and are assumed to provide the better outcomes.

\section{CONCLUSION}

In clinical practice, the diagnosis and management of patients with SCD can be improved by incorporating available knowledge of this condition. Awareness of its high prevalence in middle-age women presenting with ACS in combination with diagnostic workflow algorithms will ultimately aid to deliver an individualised treatment. Patients with SCAD also benefit from personalised counselling and assessment of their concomitant medical disorders.

Acknowledgements The first author has received a grant from Fundación Interhospitalaria Investigación Cardiovascular for conducting clinical research. The radiology department collaborated providing images of fibromuscular dysplasia of figure 1. The authors are grateful to Miguel Macaya (visual artist) for his disinterested work in creating the artery models that illustrate figure 2.

Contributors FM wrote the first draft of this manuscript. PS and NG contributed in planning the structure and content, as in reviewing the first draft. AFO, CM and JE provided key intellectual input and appraisal.

Funding This study was funded by Fundación Interhospitalaria Investigación Cardiovascular.

Competing interests None declared.

Patient consent Not required.

Provenance and peer review Not commissioned; externally peer reviewed.

Open access This is an open access article distributed in accordance with the Creative Commons Attribution Non Commercial (CC BY-NC 4.0) license, which permits others to distribute, remix, adapt, build upon this work non-commercially, and license their derivative works on different terms, provided the original work is properly cited, appropriate credit is given, any changes made indicated, and the use is non-commercial. See: http://creativecommons.org/licenses/by-nc/4.0/

\section{REFERENCES}

1. Alfonso F, Paulo M, Lennie V. Spontaneous coronary artery Dissection. JACC Cardiovasc Interv 2012;5:1062-70.

2. Eleid MF, Guddeti RR, Tweet MS, et al. Coronary artery tortuosity in spontaneous coronary artery dissection: angiographic characteristics and clinical implications. Circ Cardiovasc Interv 2014;7:656-62.

3. Lettieri C, Zavalloni D, Rossini R, et al. Management and long-term prognosis of spontaneous coronary artery dissection. Am J Cardiol 2015;116:66-73.

4. Rogowski S, Maeder MT, Weilenmann D, et al. Spontaneous coronary artery dissection: angiographic follow-up and long-term clinical outcome in a predominantly medically treated population. Catheter Cardiovasc Interv 2017;89:59-68.

5. Rashid HNZ, Wong DTL, Wijesekera H, et al. Incidence and characterisation of spontaneous coronary artery dissection as a cause of acute coronary syndrome - a single-centre Australian experience. Int J Cardiol 2016;202:336-8.

6. Nakashima T, Noguchi T, Haruta S, et al. Prognostic impact of spontaneous coronary artery dissection in young female patients with acute myocardial infarction: a report from the angina pectorismyocardial infarction multicenter investigators in Japan. Int $J$ Cardiol 2016;207:341-8.
7. McGrath-Cadell L, McKenzie P, Emmanuel S, et al. Outcomes of patients with spontaneous coronary artery dissection. Open Heart 2016;3:e000491.

8. Motreff P, Malcles G, Combaret N, et al. How and when to suspect spontaneous coronary artery dissection: novel insights from a single-centre series on prevalence and angiographic appearance. Eurolntervention 2017;12:e2236-e2243.

9. Saw J, Humphries K, Aymong E, et al. Spontaneous coronary artery dissection. J Am Coll Cardiol 2017;70:1148-58.

10. Abreu G, Galvão Braga C, Costa J, et al. Spontaneous coronary artery dissection: a single-center case series and literature review. Rev Port Cardiol 2018;37:707-13.

11. Tweet MS, Eleid MF, Best PJM, et al. Spontaneous coronary artery dissection. Circulation 2014;7:777-86.

12. Tweet MS, Hayes SN, Codsi E, et al. Spontaneous coronary artery dissection associated with pregnancy. J Am Coll Cardiol 2017;70:426-35.

13. Adlam D, Alfonso F, Maas A, et al. European Society of Cardiology, acute cardiovascular care association, SCAD study group: a position paper on spontaneous coronary artery dissection. Eur Heart J 2018;68.

14. Hayes SN, Kim ESH, Saw J, et al. Spontaneous coronary artery dissection: current state of the science: a scientific statement from the american heart association. Circulation 2018;137:e523-57.

15. Tweet MS, Gulati R, Aase LA, et al. Spontaneous coronary artery dissection: a disease-specific, social networking communityinitiated study. Mayo Clin Proc 2011;86:845-50.

16. SCAD alliance, 2017. SCAD Alliance. Available from: http://www. scadalliance.org/ [Accessed 11 Dec 2017].

17. Bucheri D, Giulia Z, Alfonso F, et al. Pulse on spontaneous coronary artery dissections: an experience-based survey. JACC CardiovasC Interv 2017;10:1468-9.

18. Pittman Wagers T, Stevens CJ, Ross KV, et al. Spontaneous coronary artery dissection (SCAD): female survivors' experiences of stress and support. J Cardiopulm Rehabil Prev 2018.

19. Liang JJ, Tweet MS, Hayes SE, et al. Prevalence and predictors of depression and anxiety among survivors of myocardial infarction due to spontaneous coronary artery dissection. J Cardiopulm Rehabil Prev 2014;34:138-42.

20. Saw J, Mancini GBJ, Humphries KH. Contemporary review on spontaneous coronary artery dissection. J Am Coll Cardiol 2016;68:297-312.

21. Al-Hussaini A, Adlam D. Spontaneous coronary artery dissection. Heart 2017;103:1043-51.

22. Tweet MS, Gulati R, Hayes SN. Spontaneous coronary artery dissection. Curr Cardiol Rep. 2016;18.

23. Vrints CJ. Spontaneous coronary artery dissection. Heart 2010;96:801-8.

24. Nishiguchi T, Tanaka A, Ozaki Y, et al. Prevalence of spontaneous coronary artery dissection in patients with acute coronary syndrome. Eur Heart J 2016;5:263-70.

25. Saw J, Aymong E, Mancini GBJ, et al. Nonatherosclerotic Coronary Artery Disease in Young Women. Can J Cardiol 2014;30:814-9.

26. Hill SF, Sheppard MN. Non-atherosclerotic coronary artery disease associated with sudden cardiac death. Heart 2010;96:1119-25.

27. Alfonso F, Paulo M, Gonzalo N, et al. Diagnosis of spontaneous coronary artery dissection by optical coherence tomography. J Am Coll Cardiol 2012;59:1073-9.

28. Paulo M, Sandoval J, Lennie V, et al. Combined Use of OCT and IVUS in spontaneous coronary artery dissection. JACC CardiovasC Imaging 2013;6:830-2.

29. Saw J. Coronary angiogram classification of spontaneous coronary artery dissection: coronary angiogram classification of spontaneous coronary artery Dissection. Catheter Cardiovasc Interv 2014;84:1115-22.

30. Adams H, Paratz E, Somaratne J, et al. Different patients, different outcomes: A case-control study of spontaneous coronary artery dissection versus acute coronary syndrome. $J$ Interv Cardiol 2018;31:41-47.

31. Elkayam U, Jalnapurkar S, Barakkat MN, et al. Pregnancyassociated acute myocardial infarction: a review of contemporary experience in 150 cases between 2006 and 2011. Circulation 2014;129:1695-702.

32. Faden MS, Bottega N, Benjamin A, et al. A nationwide evaluation of spontaneous coronary artery dissection in pregnancy and the puerperium. Heart 2016;102:1974-9.

33. Cade JR, Szarf G, de Siqueira ME, et al. Pregnancy-associated spontaneous coronary artery dissection: insights from a case series of 13 patients. Eur Heart J Cardiovasc Imaging 2017;18:54-61. 
34. Havakuk O, Goland S, Mehra A. Pregnancy and the risk of spontaneous coronary artery dissection. Circulation 2017;10:e004941.

35. Saw J, Starovoytov A, Humphries K. Canadian spontaneous coronary artery dissection cohort study. Munich, Germany, 2018.

36. Saw J, Aymong E, Sedlak T, et al. Spontaneous coronary artery dissection: association with predisposing arteriopathies and precipitating stressors and cardiovascular outcomes. Circ Cardiovasc Interv 2014;7:645-55.

37. Macaya F, Salinas P, García-González C, et al. Pregnancyassociated spontaneous coronary artery dissection: a different presentation although perhaps not such a distinct condition. J Am Coll Cardiol 2018;71:468.

38. Olin JW, Gornik HL, Bacharach JM, et al. Fibromuscular dysplasia: state of the science and critical unanswered questions: a scientific statement from the American Heart Association. Circulation 2014;129:1048-78.

39. Persu A, Giavarini A, Touzé E, et al. European consensus on the diagnosis and management of fibromuscular dysplasia. J Hypertens 2014;32:1367-78.

40. Prasad M, Tweet MS, Hayes SN, et al. Prevalence of extracoronary vascular abnormalities and fibromuscular dysplasia in patients with spontaneous coronary artery dissection. Am J Cardiol 2015;115:1672-7.

41. Toggweiler S, Puck M, Thalhammer C, et al. Associated vascular lesions in patients with spontaneous coronary artery dissection. Swiss Med Wkly 2012;142:w13538.

42. Kadian-Dodov D, Gornik HL, Gu X, et al. Dissection and aneurysm in patients w fibromuscular dysplasia. J Am Coll Cardiol 2016;68:176-85

43. Saw J, Bezerra H, Gornik HL, et al. Angiographic and intracoronary manifestations of coronary fibromuscular dysplasia. Circulation 2016;133:1548-59.

44. Reddy S, Vaid T, Ganiga Sanjeeva NC, et al. Spontaneous coronary artery dissection as the first presentation of systemic lupus erythematosus. BMJ Case Rep 2016

45. Srinivas M, Basumani P, Muthusamy R. Active inflammatory bowel disease and coronary artery dissection. Postgrad Med $J$ 2005;81:68-70.

46. Grover P, Fitzgibbons TP. Spontaneous coronary artery dissection in a patient with autosomal dominant polycystic kidney disease: a case report. J Med Case Rep 2016;10:62.

47. Cereda AF, Canova PA, Soriano FS. Spontaneous coronary artery dissection after pregnancy as first manifestation of a vascular ehlers-danlos syndrome. J Invasive Cardiol 2017;29:E67-8.

48. Canpolat U, Dural M, Atalar E. Acute inferior myocardial infarction in a young female patient with polyarteritis nodosa. Herz 2012;37:461-4.

49. Díez-Delhoyo F, Sanz-Ruiz R, Casado-Plasencia A, et al. Not just thrombi occlude coronary arteries in Behçet's disease: a case of spontaneous coronary artery dissection. Int J Cardiol 2016;214:317-9.

50. Fattori R, Sangiorgio P, Mariucci E, et al. Spontaneous coronary artery dissection in a young woman with Loeys-Dietz syndrome. Am J Med Genet A 2012;158A:1216-8.

51. Sato C, Wakabayashi K, Suzuki $\mathrm{H}$. Natural course of isolated spontaneous coronary artery dissection in Marfan syndrome. Int J Cardiol 2014;177:20-2.

52. Garcia-Bermúdez M, Moustafa A-H, Barrós-Membrilla A, et al. Repeated loss of consciousness in a young woman: a suspicious smad3 mutation underlying spontaneous coronary artery dissection. Can J Cardiol 2017:33:292.e1-292.e3.

53. Henkin S, Negrotto SM, Tweet MS, et al. Spontaneous coronary artery dissection and its association with heritable connective tissue disorders. Heart 2016;102:876-81.

54. Kaadan MI, MacDonald C, Ponzini F, et al. Prospective cardiovascular genetics evaluation in spontaneous coronary artery dissection. Circ Genom Precis Med 2018;11:e001933.

55. Camacho Freire SJ, Díaz Fernández JF, Gheorghe LL, et al. Spontaneous coronary artery dissection and hypothyroidism. Rev Esp Cardiol 2018.

56. World Health Organization, 2017. Depression and other common mental disorders: global health estimates. Available from: http://www.who.int/iris/handle/10665/254610 [Accessed 1 Nov 2017]

57. GHDx, 2018. Global health data exchange. Available from: http:// ghdx.healthdata.org/ [Accessed 31 Jan 2018].

58. Franco C, Starovoytov A, Heydari M, et al. Changes in left ventricular function after spontaneous coronary artery dissection. Clin Cardiol 2017;40:149-54.
59. Sharma S, Rozen G, Duran J, et al. Sudden cardiac death in patients with spontaneous coronary artery dissection. J Am Coll Cardiol 2017;70:114-5.

60. Templin C, Ghadri JR, Diekmann J, et al. Clinical features and outcomes of takotsubo (stress) cardiomyopathy. N Engl J Med Overseas Ed 2015;373:929-38.

61. Núñez Gil IJ, Andrés M, Almendro Delia M, Delia MA, et al Characterization of tako-tsubo cardiomyopathy in spain: results from the retako national registry. Rev Esp Cardiol 2015;68:505-12.

62. Chou AY, Sedlak T, Aymong E, et al. Spontaneous coronary artery dissection misdiagnosed as takotsubo cardiomyopathy: a case series. Can J Cardiol 2015;31:1073.e5-1073.e8.

63. Y-Hassan S, Themudo R, Maret E. Spontaneous coronary artery dissection and takotsubo syndrome: the chicken or the egg causality dilemma. Catheter Cardiovasc Interv 2017;89:1215-8.

64. Macaya F, Vedia O, Gonzalo N, et al. Misleading takotsubolike syndrome unravelled by intracoronary imaging. Eur Heart $J$ Cardiovasc Imaging 2017;18:1187.

65. Ruggiero A, Cuculo A, Centola A, et al. How should I treat an extended spontaneous coronary artery dissection in a young woman without cardiovascular risk factors mimicking Takotsubo cardiomyopathy? Eurolntervention 2016;12:e1073-6.

66. De-Giorgio F, Grassi VM, Abbate A, et al. Causation or coincidence? a case of sudden death due to spontaneous coronary artery dissection in presence of myocardial bridging. Int $J$ Cardiol 2012;159:e32-e34.

67. Wu S, Liu W, Zhou Y. Spontaneous coronary artery dissection in the presence of myocardial bridge causing myocardial infarction: an insight into mechanism. Int J Cardiol 2016;206:77-8.

68. Goel K, Tweet M, Olson TM, et al. Familial spontaneous coronary artery dissection: evidence for genetic susceptibility. JAMA Intern Med 2015;175:821.

69. Smyth A, O'Donnell M, Lamelas P, et al. Physical activity and anger or emotional upset as triggers of acute myocardial infarction: the interheart study. Circulation 2016;134:1059-67.

70. Fahmy P, Prakash R, Starovoytov A, et al. Pre-disposing and precipitating factors in men with spontaneous coronary artery dissection. JACC Cardiovasc Interv 2016;9:866-8.

71. Velusamy M, Fisherkeller M, Keenan ME, et al. Spontaneous coronary artery dissection in a young woman precipitated by retching. J Invasive Cardiol 2002;14:198-201.

72. Sivam S, Yozghatlian V, Dentice R, et al. Spontaneous coronary artery dissection associated with coughing. J Cyst Fibros 2014;13:235-7.

73. Dworakowski R, Desai J, MacCarthy P. Spontaneous left main coronary artery dissection while skiing at altitude. Eur Heart $J$ 2009;30:868

74. Balakrishnan K, Scott P, Oliver L. A confluence of circumstances: a case of IVF, extreme exercise and spontaneous coronary artery dissection. Int J Cardiol 2016;203:76-7.

75. Katikaneni PK, Akkus NI, Tandon N, et al. Cocaine-induced postpartum coronary artery dissection: a case report and 80-year review of literature. J Invasive Cardiol 2013;25:E163-6.

76. Afzal AM, Sarmast SA, Weber NA, et al. Spontaneous coronary artery dissection in a 22-year-old man on lisdexamfetamine. Proc 2015;28:367-8.

77. Keir ML, Dehghani P. Corticosteroids and spontaneous coronary artery dissection: a new predisposing factor? Can J Cardiol 2016;32:395.e7-395.e8.

78. Mehta LS, Beckie TM, DeVon HA, et al. Acute myocardial infarction in women: a scientific statement from the American Heart Association. Circulation 2016;133:916-47.

79. Prakash R, Starovoytov A, Heydari M, et al. Catheterinduced iatrogenic coronary artery dissection in patients with spontaneous coronary artery dissection. JACC Cardiovasc Interv 2016:9:1851-3.

80. Macaya F, Salazar CH, Pérez-Vizcayno MJ. Feasibility and safety of intracoronary imaging in spontaneous coronary artery dissection. Munich, Germany, 2018.

81. Macaya F, Salinas P, Gonzalo N, et al. Repeated intracoronary imaging in spontaneous coronary artery dissection: weighing benefits and risks. JACC Cardiovasc Interv 2017;10:2342.

82. Griffin A, Navar AM, Crawford L, et al. A case of spontaneous coronary artery dissection diagnosed by coronary computed tomography angiography. $J$ Cardiovasc Comput Tomogr 2018;12:88-9.

83. Tweet MS, Akhtar NJ, Hayes SN, et al. Spontaneous coronary artery dissection: findings on coronary computed tomography angiography. Eur Heart J Acute Cardiovasc Care 2018;2048872617 753799:204887261775379. 
84. Das Neves BC, Núñez-Gil IJ, Alfonso F, et al. Evolutive recanalization of spontaneous coronary artery dissection: insights from a multimodality imaging approach. Circulation 2014;129:719-20.

85. Roura G, Ariza-Solé A, Rodriguez-Caballero IF, et al. Noninvasive follow-up of patients with spontaneous coronary artery dissection with ct angiography. JACC Cardiovasc Imaging 2016;9:896-7.

86. Shiran A, Adawi S, Rubinshtein R, et al. Non-invasive management of post-partum spontaneous left main coronary artery dissection using cardiac computed tomography angiography. Eur Heart $J$ Cardiovasc Imaging 2017;18:1152.

87. Gonzalo N, Macaya F, Gómez de Diego JJ, et al. Long-term outcome of a spontaneous coronary artery dissection treated with a bioresorbable scaffold. Eurolntervention 2017;13:994-5.

88. Agewall S, Beltrame JF, Reynolds HR, et al. ESC working group position paper on myocardial infarction with non-obstructive coronary arteries. Eur Heart J 2017;38:143-53.

89. Martins JL, Afreixo V, Santos L, et al. Medical treatment or revascularisation as the best approach for spontaneous coronary artery dissection: A systematic review and meta-analysis. Eur Heart J Acute Cardiovasc Care 2017:204887261770650.

90. Mahmoud AN, Taduru SS, Mentias A, et al. Trends of incidence, clinical presentation, and in-hospital mortality among women with acute myocardial infarction with or without spontaneous coronary artery dissection: a population-based analysis. JACC Cardiovasc Interv 2018;11:80-90.

91. Bhatt DD, Kachru R, Gupta S, et al. Recurrent chest pain after treatment of spontaneous coronary artery dissection: An enigma. Indian Heart J 2015;67(Suppl 3):S18-S20.

92. Tweet MS, Codsi E, Best PJM, et al. Menstrual chest pain in women with history of spontaneous coronary artery dissection. $J$ Am Coll Cardiol 2017;70:2308-9.

93. Okuya Y, Fukushima K, Hori Y, et al. Fenestration using a scoring balloon Scoreflex $®$ as troubleshooting for acute vessel closure due to intramural hematoma complication in percutaneous coronary intervention. Cardiovasc Interv Ther 2015;30:311-4.

94. Ito $\mathrm{T}$, Shintani $\mathrm{Y}$, Ichihashi $\mathrm{T}$, et al. Non-atherosclerotic spontaneous coronary artery dissection revascularized by intravascular ultrasonography-guided fenestration with cutting balloon angioplasty. Cardiovasc Interv Ther 2017;32:241-3.

95. Conrotto F, D'Ascenzo F, Cerrato E, et al. Safety and efficacy of drug eluting stents in patients with spontaneous coronary artery dissection. Int J Cardiol 2017;238:105-9.

96. Macaya F, Peral V, Alameda M. Bioresorbable scaffolds to treat spontaneous coronary artery dissection. Circulation 2015:9:e003133.

97. Ielasi A, Cortese B, Tarantini G, et al. Sealing spontaneous coronary artery dissection with bioresorbable vascular scaffold implantation: Data from the prospective "Registro Absorb Italiano" (RAl Registry). Int J Cardiol 2016;212:44-6.

98. Macaya F, Salinas P, Gonzalo N, et al. Long-term follow-up of spontaneous coronary artery dissection treated with bioresorbable scaffolds. Eurolntervention 2018.

99. Serruys PW, Chevalier B, Sotomi Y, et al. Comparison of an everolimus-eluting bioresorbable scaffold with an everolimuseluting metallic stent for the treatment of coronary artery stenosis (ABSORB II): a 3 year, randomised, controlled, single-blind, multicentre clinical trial. Lancet 2016;388:2479-91.

100. Kereiakes DJ, Ellis SG, Metzger C, et al. 3-Year clinical outcomes with everolimus-eluting bioresorbable coronary scaffolds: The ABSORB III Trial. J Am Coll Cardiol 2017;70:2852-62.

101. Quadri G, Tomassini F Cerrato F First reported case of magnesium-made bioresorbable scaffold to treat spontaneous left anterior descending coronary artery dissection: MagnesiumMade BRS to Treat Spontaneous LAD Coronary Artery Dissection. Catheter Cardiovasc Interv 2017.

102. Alkhouli M, Cole M, Ling FS. Coronary artery fenestration prior to stenting in spontaneous coronary artery dissection: Coronary Artery Fenestration in Patients with SCAD. Catheter Cardiovasc Interv 2016;88:E23-7.

103. Fabris E, Kennedy MW, Sinagra G, et al. Optical coherence tomography for strategy planning and staged optimization of spontaneous coronary artery dissection. Eur Heart J Cardiovasc Imaging 2017;18:939.

104. Mele M, Langialonga T, Maggi A, et al. Self-expanding stent for spontaneous coronary artery dissection: a rational choice. $J$ Cardiovasc Med 2016;17(Suppl 2):e254-e256.
105. Lempereur M, Fung A, Saw J. Stent mal-apposition with resorption of intramural hematoma with spontaneous coronary artery dissection. Cardiovasc Diagn Ther 2015;5:323.

106. Mori H, Kutys R, Romero M, et al. Stenting of Spontaneous Coronary Artery Dissection From a Pathological Point of View. Circ Cardiovasc Interv 2016;9:e004549.

107. Nishiguchi T, Tanaka A, Taruya A, et al. Prognosis of spontaneous coronary artery dissection treated by percutaneous coronary intervention with optical coherence tomography. J Cardiol 2017;70:524-9.

108. Valgimigli M, Bueno $\mathrm{H}$, Byrne RA. ESC focused update on dual antiplatelet therapy in coronary artery disease developed in collaboration with EACTSThe Task Force for dual antiplatelet therapy in coronary artery disease of the European Society of Cardiology (ESC) and of the European Association for Cardio-Thoracic Surgery (EACTS). Eur Heart J 2017.

109. Ibanez B, James S, Agewall S. 2017 ESC Guidelines for the management of acute myocardial infarction in patients presenting with ST-segment elevation: The Task Force for the management of acute myocardial infarction in patients presenting with ST-segment elevation of the European Society of Cardiology (ESC). Eur Heart J 2017.

110. Roffi M, Patrono C, Collet JP, et al. 2015 ESC Guidelines for the management of acute coronary syndromes in patients presenting without persistent ST-segment elevation: Task Force for the Management of Acute Coronary Syndromes in Patients Presenting without Persistent ST-Segment Elevation of the European Society of Cardiology (ESC). Eur Heart J 2016;37:267-315.

111. Tweet MS, Hayes SN, Pitta SR, et al. Clinical features, management, and prognosis of spontaneous coronary artery dissection. Circulation 2012;126:579-88.

112. Michelis KC, Olin JW, Kadian-Dodov D, et al. Coronary artery manifestations of fibromuscular dysplasia. J Am Coll Cardiol 2014:64:1033-46.

113. Lather HD, Gornik HL, Olin JW, et al. Prevalence of intracrania aneurysm in women with fibromuscular dysplasia: a report from the US registry for fibromuscular dysplasia. JAMA Neurol 2017;74:1081.

114. Macaya F, Aldazábal A, Moreu M, et al. Screening of systemic arteriopathy in patients with spontaneous coronary artery dissection. Eur Heart J Cardiovasc Imaging 2018;19:357

115. Macaya F, Moreu M, Aldazábal A. Prevalence of systemic arteriopathy diagnosed with magnetic resonance angiography in patients with spontaneous coronary artery dissection. Munich, Germany, 2018.

116. Walkoff L, Brinjikji W, Rouchaud A, et al. Comparing magnetic resonance angiography (MRA) and computed tomography angiography (CTA) with conventional angiography in the detection of distal territory cerebral mycotic and oncotic aneurysms. Interv Neuroradiol 2016;22:524-8.

117. Thompson BG, Brown RD, Amin-Hanjani S, et al. Guidelines for the management of patients with unruptured intracranial aneurysms: a guideline for healthcare professionals from the american heart association/american stroke association. Stroke 2015;46:2368-400.

118. Willoteaux S, Faivre-Pierret M, Moranne O, et al. Fibromuscular dysplasia of the main renal arteries: comparison of contrast-enhanced MR angiography with digital subtraction angiography. Radiology 2006;241:922-9.

119. Savard S, Azarine A, Jeunemaitre X, et al. Association of smoking with phenotype at diagnosis and vascular interventions in patients with renal artery fibromuscular dysplasia. Hypertension 2013:61:1227-32.

120. Kim ES, Serhal M. The diagnosis and treatment of fibromuscular dysplasia: an update for cardiologists. Curr Treat Options Cardiovasc Med 2016;18:37.

121. Chou AY, Prakash R, Rajala J, et al. The first dedicated cardiac rehabilitation program for patients with spontaneous coronary artery dissection: description and initial results. Can J Cardiol 2016:32:554-60.

122. Krittanawong $\mathrm{C}$, Tweet MS, Hayes SE, et al. Usefulness of cardiac rehabilitation after spontaneous coronary artery dissection. Am J Cardiol 2016;117:1604-9.

123. Tweet MS, Hayes SN, Gulati R, et al. Pregnancy after spontaneous coronary artery dissection: a case series. Ann Intern Med 2015;162:598-600.

124. Main A, Starovoytov A, Sabbaghan A. Characteristics of extension and de novo recurrent spontaneous coronary artery dissection. Eurolntervention J Eur Collab Work Group Interv Cardiol Eur Soc Cardiol 2017. 